\title{
Sağlık Okuryazarlığı Kavramı ve Sağlık Haberlerini Doğru Okumak
}

\author{
Öğr.Gör. Dr. Seçil Utma ${ }^{1^{*}}$
}

Gelis tarihi: 26.09 .2019

Kabul tarihi: 30.10 .2019

\section{Atıf bilgisi:}

IBAD Sosyal Bilimler Dergisi

Sayı: 5 Sayfa: 223-231

Yıl: 2019 Dönem: Güz

This article was checked by iThenticate. Similarity Index 13\%

${ }^{1}$ Adnan Menderes Üniversitesi, Türkiye, secilut@hotmail.com

ORCID ID 0000-0002-5003-2137.

\section{öz}

Yeniliklerin kamuoyuna duyurulmasında en etkili araçların başında yer alan medya, sağlık konusunda da benzer işlevini yerine getirmektedir. Sağlık temalı yayınlar hedef kitle tarafindan dikkatle takip edilmekte, günlük yaşam pratikleri içerisinde kendisine yer bulmaktadır. Toplumun sağlık bilincinin yükselmesinde önemli bir yer tutan sağlık okuryazarlığı kavramı son yıllarda giderek tartışılan bir alan olarak karşımıza çıkmaktadır. Medyadaki sağlık haberlerini doğru okumak, sağlıklı 'sağlık haberciliği' adına önem taşımaktadır. Doğru ve güvenilir sağlık haberlerine ulaşmada sağlık okuryazarlığının önemi vurgulanan çalışmada, sağlık okuryazarlığı kavramı tanımlanarak, güvenilir ve doğru habercilik konusunda yaşanan sıkıntılar kuramsal olarak ele alınmakta, çözüm önerileri sunulmaktadır.

Anahtar Kelimeler: Medya, Sağlık Haberleri, Sağlık Okuryazarlığı.

\footnotetext{
* Sorumlu yazar
} 


\title{
Correctly Reading The Concept of Health Literacy and Health News
}

\author{
Lec. Dr. Seçil Utma
}

First received: 26.09 .2019

Accepted: 30.10 .2019

\section{Citation:}

IBAD Journal of Social Sciences

Issue: 5

Pages: $223-231$

Year: 2019

Session: Fall

This article was checked by iThenticate. Similarity Index 13\%

${ }^{1}$ Adnan Menderes University, Turkey, secilut@hotmail.com

ORCID ID 0000-0002-5003-2137.

\footnotetext{
* Corresponding Author
}

\begin{abstract}
Media, which is one of the most effective tools for publicizing innovations, has a similar function in health. Health-themed publications are carefully followed by the target audience and find their place in daily life practices. The concept of health literacy, which has an important place in raising the health awareness of the society, has emerged as an increasingly debated field in recent years. Reading the health news in the media correctly is important for healthy 'health reporting'. In the study, which emphasizes the importance of health literacy in achieving accurate and reliable health news, the concept of health literacy is defined and the problems experienced in reliable and correct reporting are handled theoretically and solutions are offered.
\end{abstract}

Keywords: Media, Health News, Health Literacy. 


\section{GíRiş}

Son yıllarda dünya genelinde medyada sağlıkla ilgili haberlerin nicelik olarak arttığı göze çarpmaktadır. Medya kuruluşları sağlı alanıyla ilgili enformasyonun kamuoyuna ulaşmasını sağlamakta, bu bilgiler geniş halk kesimleri tarafından ilgiyle takip edilmektedir.

Sağlıklı bireyler olmanın zeminini hazırlayan en önemli unsurlardan biri, kendi sağlığını koruma konusunda bilinçli olmaktan geçmektedir. Bu aşamada doğru sağllk bilgisine ulaşmak önem taşımaktadır. İnsan yaşamıyla yakından ilişkili olan sağlık gibi önemli bir konuda verilen bilgilerin güvenilir ve doğru olması hayati önem taşımaktadır. Kitle iletişim araçları aracılığıyla geniş halk kesimlerine ulaşan sağlık mesajlarının doğru olmayan ya da eksik enformasyondan oluşması, sağlık okuryazarlı̆̆ 1 kavramının önem kazanmasına yol açmıştır. Sağlık personeli ile hasta arasındaki yüz yüze iletişimle başlayıp, kitle iletişim araçlarına kadar uzanan geniş bir yelpazede gerçekleşen sağlık iletişiminde, bireylerin sağlıkla ilgili enformasyonları doğru anlamaları kadar, edindikleri bilgileri uygun biçimde kullanmaları noktasında kilit rol oynayan sağlık okuryazarlığı, bilgiye erişimin giderek kolaylaştığı, bireylerin internet aracılığıyla sürekli enformasyon bombardımanına maruz kaldığı göz önüne alındığında önemi giderek artan bir kavram olarak karşımıza çıkmaktadır.

Sağlık okuryazarlığı düzeyinin yetersiz olması, bireysel ve sosyal açıdan birtakım riskler oluşturmakta, verilen sağlık hizmetlerinin istenilen sonuca ulaşmasına engel olmaktadır. Herhangi bir ilacın hangi dozlarda alınması gerektiğinden, tahlil sonuçlarını anlamaya, tansiyon ölçümündeki rakamların anlamından, belli alışkanlıkların getirdiği risklerin bilincinde olmaya kadar birçok konu, sağlık okur yazarlığ

\section{SAĞLIK HABERLERINDE DOĞRULUK SORUNU}

Toplumun büyük kesimini yakından ilgilendiren sağlı haberleri, günümüz medya endüstrileri tarafından sıklıkla kullanılmakta, izleyici toplama, satışları arttırma gayesiyle haberler sansasyonel bir formatta verilmektedir. Tüketime dayalı bir yaşam tarzını empoze eden bu tarz haberler, insanların nasıl yaşayacaklarına, ne yiyeceklerine, gündelik hayatlarını nasıl düzenleyeceklerine ilişkin tavsiyeler sunarak, mevcut endüstriyel yapıların çıkarlarına hizmet etmektedir. Medya kuruluşları reklam gelirlerini arttırma kaygıları içerisinde insan hayatı ile yakından ilişkili olan sağlık haberciliği alanında da abartılı, gerçek dışı söylemlerden uzak durmamaktadır.

Yeniliklerin kamuoyuna duyurulmasında en etkili araçların başında yer alan medya, sağlık konusunda da benzer işlevini yerine getirmektedir. Sağlık temalı yayınlar hedef kitle tarafindan dikkatle takip edilmekte ve medya metinlerinde yer alan enformasyon, gündelik yaşamda bireyler tarafindan hayata geçirilmektedir (Kaya vd., 2011, s. 51).

Medya kuruluşları sağlık haberciliği konusunda sansasyonel bir yayıncılık anlayışını benimsemekte, olayları haberleştirirken konunun ilgi çekecek, şok yaratacak yönlerini ön plana çıkartarak, olayları adeta seyirlik bir anlatıya dönüştürmektedir. Diğer alanlarda olduğu gibi benzer şekilde sağlik haberciliği alanında da uzman görüşüne başvurulan haberlerin oranının az sayıda olduğu, sunulan enformasyonun genellikle anonim kaynaklara referansla meşrulaştırıldığı (uzmanlar uyarıyor, doktorlar öneriyor, bilim insanları sıraladı gibi ) ya da bilimsel dayanaktan yoksun ifadelerle kurgulandığı göze çarpmaktadır. Buna ek olarak haberlerde kamu yararının göz ardı edilmesi nedeniyle, doğrudan ve örtülü reklam ve tanıtımların kayda değer oranda yer aldığı görülmektedir. $\mathrm{Bu}$ durum topluma yanlış, eksik ve yanlı bir şekilde yapılandırılmış enformasyon sunulmasına neden olmaktadır.

Sağlık haberciliği alanında genelde akademik unvanlarıyla ya da üyesi oldukları hastane, bilimsel kuruluş vb. gibi uzmanlıklarıyla medyada yer alan sağlık çalışanları, okuyucu ve izleyicilere sağlıklı yaşam reçeteleri sunmaktadır. Dolayısıyla birey gün boyu medyada yapılan yayınlar aracılığıyla yaşamını disipline etmekte, doğru beslenmenin, doğru ilişki kurmanın, mutlu olmanın reçetelerini uzmanlardan almaktadır.

Medyada sağlık ile ilgili metinler bilgilendirme ve haber verme işlevinden çok, uzmanların aracılığıyla yönlendirici ve düzenleyici bir formatta yer almaktadır. Uzmanlar tarafından verilen bilgiler doğru ve 
kesin olma anlamlarını taşırken, sağlık çalışanlarının bilgi birikimlerinden aldıkları güçle toplum sağlığı üzerinde söz sahibi oldukları görülmektedir (Hüler, 2016, s. 44).

Medya aracıllı̆ıyla sunulan sağlik enformasyonunda ciddi sorunlar ortaya çıkmakta, yoğun bilgi bombardımanına maruz kalan bireyler hangi bilgilerin gerçek olduğu konusunda şüpheye düşmektedir. Sosyal medya kanaliyla hedef kitlelere ulaşan bilgiler söz konusu olduğunda durumun ciddiyeti daha da artmakta, bu platformlarda öneriler uzmanların yanı sıra hastaların kendi deneyimlerini bir başka hastaya aktarması şeklinde karşımıza çıkmaktadır. Hastalığına çare arayan kişiler medya yoluyla edindiği bu bilgileri çok fazla araştırmadan kabullenip, kendi ya da bir yakını üzerinde deneme yoluna gitmektedir. Örneğin tüm dünyada genel bir halk sağlı̆̆ı sorunu haline gelen obezite konusunda çözüm reçeteleri sunan çok farklı enformasyon ile karşılaşmak mümkündür. Özellikle internet ortamında yer alan zayıflamaya yönelik diyet listeleri, spor programları, bitkisel ürünler ya da ilaçlar insan sağlığını tehdit ederek, ciddi sorunlara yol açabilmektedir. Henüz sonuçlanmamış araştırmaların medya tarafindan kesin tedavi yöntemleri gibi sunulması, her şeyden önce hastaların zarar görmesine yol açmaktadır.

\section{SAĞLIK OKURYAZARLIĞI KAVRAMI}

Bireyler yaşamları süresince sağlıkla ilgili konularda çok sayıda enformasyon ile karşılaşmakta, hastalıkların tedavi süreci, ilaç kullanımı gibi konularda karar vermek durumunda kalmaktadır. $\mathrm{Bu}$ kararların bir bölümü, hasta ve sağlık profesyonelleri arasındaki yüz yüze iletişim esnasında verilirken, önemli sayıda enformasyon medya aracılı̆g ile bireylere ulaşmaktadır. Bu durum sağlık hizmetlerine erişim, sağlık bilgisini anlama ve yorumlama konusunda bir takım sıkıntıların yaşanmasına yol açmaktadır.

Son yıllarda teknolojik gelişmelere paralel olarak hastalık, hastalıklardan korunma yolları ve tedavi biçimlerinde bir değişim görülmekte, bu gelişim sağlık personeli ile hastalar arasındaki iletişimin de doğasını değiştirmektedir. Hastalar ile sağlık personeli arasındaki iletişim sürecinin sağlıklı işleyebilmesi, öncelikle her iki tarafın birbirini doğru anlaması ile mümkün olabilmektedir. Hastaların ilaç ile ilgili bilgileri doğru anlayamaması nedeniyle zamanında ve doğru biçimde almaması, kendisine yönelik olarak hazırlanan basılı materyalleri doğru değerlendirmemesi ciddi sağlik sorunlarına yol açabilmektedir. Sağlık iletişiminin önemli konularından biri olan sağlık okuryazarlığı kavramı, bu açıdan büyük önem taşımaktadır (Parker vd., 1995, s. 537).

Bireylerin sağlıkla ilgili enformasyonları doğru anlamaları kadar, edindikleri bilgileri uygun biçimde kullanmaları noktasında kilit rol oynayan sağlık okuryazarlığı, bilgiye erişimin giderek kolaylaştığı, bireylerin internet aracılığıyla sürekli enformasyon bombardımanına maruz kaldığı göz önüne alındığında önemi giderek artan bir kavram olarak karşımıza çıkmaktadır.

İlk kez 1974 yılında S. K. Simonds tarafindan Bir Sosyal Politika Olarak Sağlık Okuryazarlı̆̆g (Health Education as Social Policy) adlı makalede (Simonds, 1974, s. 1-25 akt: Ratzan, 2001, s. 210; Selden vd., 2000, s. 5) kaleme alınan sağlık okuryazarlığı kavramı; 2000'li yıllardan itibaren birçok çalışmaya konu olmuştur. Sağlıkla ilgili konularda doğru kararlar alabilme becerisine sahip olmak için gerekli bilgi altyapısını ifade eden bir kavram olan sağlık okuryazarlığı Amerikan Tip Kurumu (AMA-The American Medical Association) tarafından reçeteleri, randevu kâğıtlarını ve să̆llğa ilişskin diğer önemli materyalleri okuyup anlayabilme becerisi olarak tanımlanmıştır. Yine ABD'de DHHS (Hastalıkların Önlenmesi ve Sağlığın Geliştirilmesi Dairesi) tarafından 2010 yılında Sağllk Okuryazarlı̆̆ını İileştirmeye Yönelik Ulusal Eylem Planı hazırlanmıștır. Eylem planı ABD’nin Sağlıklı İnsanlar 2020 (Healthy People 2020) hedefleri içerisinde sağlık okuryazarlığının yükseltilmesini önemli bir hedef olarak ortaya koymaktadır. Bu belgeye göre sağlık okuryazarlığı; insanların uygun sağllk kararlarını vermek için gerekli olan temel sağllk bilgileri ve hizmetlerini elde etme, kullanma ve anlama kapasitesine sahip olma düzeyi olarak ele alınmıştır.

Parvanta vd. ise sağlık okuryazarlığın sağllkla ilgili karmaşık enformasyonları anlama ve kullanma yeteneği olarak tanımlamaktadır (2011, s. 120). Nutbeam'e göre ise sağlık okuryazarlığı, broşürleri okumak ve randevu almaktan daha geniş bir anlama sahiptir. Sağlık okuryazarlığı; bireylerin sağlık enformasyonuna ulaşmalarını sağlamak ve bunu etkili biçimde kullanma kapasitelerini geliştirmek 
konusunda kritik önem taşımaktadır. Bu çerçevede değerlendirildiğinde sağlık okuryazarlığının bireysel ve sosyal açıdan bir takım yararları bulunmaktadır (Nutbeam, 2001, s. 264; Zarcadoolas, 2005, s. 96). Sağlik okuryazarlığı kavramı toplumun her kesimini yakından ilgilendirmekte, mevcut sağlık sistemi ile kavram arasında önemli bir bağ bulunmaktadır (Ratzan, 2001, s. 210).

Tüm bu tanımlardan hareketle sağlık okuryazarlı̆̆ı; bireylerin kendileri ve toplum sağlı̆g ile ilgili karar ve davranışların yönlendiren, temel sağllk hizmetleri konusundaki bilgilere erişserek, bunların doğru şekilde anlamaları ve kullanmaları konusundaki beceri olarak karşımıza çıkmaktadır (Sezgin, 2011, s. 141).

Dijital teknolojinin giderek yaygınlık kazandığı günümüzde internet ortamında karşılaşılan sağlık içerikli haberlerin doğruluğu ve güvenilirliği önemli bir sorun olarak karşımıza çıkmaktadır. Sağlık bilgisinin yayıldığı alanların başında yer alan sosyal medya ortamlarında yer alan bilgileri doğru bir şekilde değerlendirmek noktasında, sağlık okuryazarlığı becerisi önemli bir yeti olarak karşımıza çıkmaktadır.

Sağlık okuryazarlı̆̆ kavramı, Nutbeam tarafindan işlevsel, etkileşimli ve eleştirel sağlık okuryazarlığı olarak sınıflandırılmıştır (2001, s. 460). Bireyleri sağlik riskleri konusunda aydınlatmayı amaçlayan işlevsel sağllk okuryazarlı̆g sağlık sistemi konusunda bireyleri bilgilendirmekte ve sağlik okuryazarlığının ilk düzeyi olarak görülmektedir. Bireyin bilgi düzeyi kapasitesini arttırarak, öz yeterliliğini güçlendirmeyi amaçlayan etkileşimli sağlık okuryazarlığı ise bireysel düzeyde kazanımı hedeflemektedir. Nutbeam'ın sınıflandırmasında son olarak ele alınan eleştirel sağlık okuryazarliğl ise bireyin gerek sağlık hizmeti sunanlardan. gerekse de medyadan edindiği sağlık enformasyonlarını doğru yorumlaması becerisini kapsamaktadır. Birey verilen enformasyonları doğru bir şekilde anlamlandırdığı takdirde, hem bireysel hem de toplumsal açıdan kazanımlar sağlanmış olacaktır (Nutbeam, 2001, s. 265; Osborne, 2005, s. 2).

Sağlıkla ilgili konularda verilen enformasyonların karmaşık olması, bu bilgilerin ilgili kesimler tarafından doğru şekilde anlaşılmasını güçleştirmekte, özellikle düşük sağlık okuryazarlık seviyesine sahip bir bireyin tıbbi konulardaki materyalleri okuyarak doğru kararlar alması zorlaşmaktadır. Verilen tedavinin kalitesi, riskleri, doğru ilaç kullanımı, test/tahlil sonuçları gibi konular sağlık okuryazarlığı kavramı ile yakından ilgili olup, hastaların temel bazı becerilere sahip olmaları bu açıdan önem taşımaktadır. Özellikle son yıllarda medyada sağlıkla ilgili haberlerin sayısında görülen artış göz önüne alındığında medyadaki sağlıkla ilgili içeriklerin doğru değerlendirilmesi, sağlık okuryazarlığı açısından büyük önem taşımaktadır. Medyada izlenen, okunan veya işitilen her şeye kuşkuyla yaklaşılması, bunların öncelikle kurgusal olduğunun bilinmesini temel alan medya okuryazarlığı, bu içeriklerin doğal olmadığını ve değiştirilebileceğine işaret etmektedir (Türkoğlu, 2007, s. 278). Kavram; medya metinlerinin çözümlenmesinden çok, bu metinlerin kimler tarafından, neden, hangi koşullar tarafından üretildiği konusunda farkındalık yaratmayı amaçlamaktadır (Binark \& Gencel-Bek, 2007, s. 104).

Sağlık okuryazarlığı bireyin kültürel altyapısı ile de yakından ilişkili olup, birey kendisine verilen enformasyonu, kültürel birikimine göre değerlendirmektedir. Bireyler sağlık enformasyonunu yorumlama noktasında inançlarını, alışkanlıklarını, dünya görüşlerini kısaca kendi kimliklerini ortaya koymaktadır. Birey hastalığın nedenleri ve korunma yolları, tedavi ve ilaçlar ile ilgili bilgileri, sağlık teknolojilerini nasıl kullanacağını, içinde bulunduğu kültürel yapıya göre değerlendirmektedir. Sağlık enformasyonları konusundaki inanç ve tutumların oluşması noktasında kültür, önemli bir role sahiptir.

\subsection{Sağlık Okuryazarlığında Sorunlar ve Çözümler}

Tıbbi enformasyonların karmaşıklığı hasta ve sağlık personeli arasındaki iletişimi olumsuz yönde etkilerken, bu durum hastanın kendine olan güveninin azalmasına yol açmaktadır. Sağlık okuryazarlığı seviyesi düşük olan bireylerin utanma, korku, kendini ifade edememe endişesi ile sağlık hizmeti sunanlarla sınırlı iletişim kurdukları göze çarpmaktadır. Bunun sonucu olarak da bireyler, bu bilgi eksikliğini aile, arkadaş, medya gibi kanallardan tamamlamaya çalışmaktadır. Eksik ya da yanlış anlaşılmış enformasyon, ölüm dahil istenmeyen durumlara sebep olabilmektedir. Medyada sağlığa ilişkin enformasyonun çoğunlukla reyting ve tiraj kaygısıyla basite indirgenerek verilmesi, ciddi 
tehlikeleri beraberinde getirmektedir. Kendilerini bilgili hisseden bireylerin bu inançla başkalarını yönlendirmeleri olasılığı da önemli bir sorun olarak karşımıza çıkmaktadır. Benzer şekilde sağlık okuryazarlığ becerileri gelişmemiş bireyler, daha sık veya uzun süre hastaneye giderek, daha fazla sağlık harcaması yapmak zorunda kalabilmektedir.

Herhangi bir ilacın hangi dozlarda alınması gerektiğinden, tahlil sonuçlarını anlamaya, tansiyon ölçümündeki rakamların anlamından, belli alışkanlıkların getirdiği risklerin bilincinde olmaya kadar birçok konu sağlık okuryazarlığı ile yakından ilgilidir. Düşük sağlık okuryazarlığı, hastaneleri gereksiz ziyaret eden insan sayısını artırırken, sağlık bakım harcamalarının artmasına yol açmaktadır. Düşük sağlık okuryazarlı̆̆ çoğunlukla başarısız olmaktadır.

Sağlıkla ilgili konularda yer alan bilgilerin her zaman doğruyu yansıtmadığı konusunda farkındalık yaratabilmenin yolu sağlı okuryazarllğg konusunda bilinçlenmekten geçmektedir. Bu okuryazarlık becerisine sahip olmayan bireyler kendisine sunulan enformasyonu koşulsuz olarak kabullenebilmekte, bu durum birtakım tehlikeleri beraberinde getirmektedir. Özellikle son y1llarda internet kullanımının yaygınlaşması, yaşanan bilgi kirliliği içerisinde doğru enformasyona ulaşma konusunda sıkıntılara yol açmaktadır. İnternette yer alan sağlıkla ilgili bilgilerin karmaşıklığı ve yoğunluğu, hastanın yanlış bilgilenmesine neden olabilmektedir. Kullanıcılara çok kısa sürede istediği bilgilere ulaşma imkanı sunan internet, konu sağlık olunca en cazip araçlardan biri haline gelmektedir.

Medyada yer alan enformasyonun güvenilirliği açısından kaynağın belirtilmesi büyük önem taşımaktadır. Sağlıkla ilgili konularda bu konu üzerinde hassasiyetle durmak gerekmektedir. Başta televizyon olmak üzere internet üzerinden veya yazılı basında, sağlıkla ilgili konularda bilgi veriyormuş izlenimi yaratılarak, ilaç, ürün, tedavi reklamlarının yapıldı̆̆ı görülmektedir. Burada reklam yapan kişiler reklamını yaptıkları tedavi ya da ürünlerin olumlu özelliklerini ön plana çıkararak, olumsuz yönlerini saklama eğilimi göstermektedir. Sağlık okuryazarlığı düzeyi düşük olan bireyler hangi bilgilerin gerçek, hangilerinin kurgu olduğu konusunda sağlıklı bir değerlendirme yapamamaktadır.

Sağlık-Sen Stratejik Araştırmalar Merkezi tarafından gerçekleştirilen sağlık okuryazarlı̆̆ çalışması dikkate değer sonuçlar ortaya koymaktadır. Ülkemizdeki yetişkin nüfusun sağlık okuryazarlığ düzeyini belirlemek amacıyla 23 ilde 5 bin kişi üzerinde gerçekleştirilen anket çalışmasına göre, toplumun sadece üçte biri yeterli sağlık okuryazarlık düzeyine sahip durumdadır. Ankete verilen yanıtlar sağlık okuryazarlığı düzeyinin Orta ve Doğu Anadolu bölgesinde en düşük, Ege bölgesinde en yüksek olduğunu ortaya koymaktadır. Bölgesel farklılıkların yanı sıra kişisel özelliklerin de sağlık okuryazarlı̆g 1 düzeyinde belirleyici olduğu vurgulanan çalışmada, yaş arttıkça ve eğitim düzeyi düştükçe sağlık okuryazarlığı seviyesinde de azalma olduğu vurgulanmıştır (Durusu Tanrıöver, 2014).

Sağlık alanında düşük okuryazarlık seviyesine sahip olmak tüm dünyada tartışılan bir sorun olarak karşımıza çıkmaktadır. Bu konuda hasta dışında, sağlık hizmeti sunanlardan, özel sektör, sivil toplum örgütleri ve medyaya kadar ilgili tüm kesimlere büyük sorumluluk düşmektedir.

Sağlık okuryazarlığının geliştirilmesi konusunda sağlık profesyonellerinin hastalarla doğru iletişim kurması büyük önem taşımaktadır. Bu konuda çalışanların sözlü dil becerilerini geliştirmeleri gerekmektedir (Parker, 2005, s. 281). Hedef kitle olarak sadece yetersiz okuryazarlık düzeyine sahip olanlara değil, aynı zamanda sağlık konusu ile yakından ilgilenen kesimlere de odaklanılmalıdır.

Sağlık okuryazarlığının geliştirilmesi noktasında halkla ilişkiler stratejilerinden de yararlanılmalı, ilgili kesimlerle ortak projeler hayata geçirilmelidir. Medya sağlık konusunda enformasyon akışının sağlandığı önemli araçlardan biridir. Bu nedenle medyanın toplumun sağlık okuryazarlık seviyesinin yükselmesinde büyük önemi bulunmaktadır. Sağlıkla ilgili konularda haber programlarının hazırlanmasında bu düşünceden hareket ederek, toplumun sağlık bilincinin arttırılmasına yönelik yayıncılık anlayışı benimsenmelidir. 


\section{SONUÇ}

Temel misyonu kamuoyunu bilgilendirme olan medya kuruluşları yeniliklerin duyurulması konusunda da en etkili araçların başında gelmektedir. Sağlık gibi insan hayatıyla yakından ilgili olan bir alanda bu bilgilendirme işlevi daha da önem kazanmakta, yapılan yayınlar ile bireyler umut ya da umutsuzluğa sürüklenebilmektedir. Sağlık temalı yayınlar hedef kitle tarafından dikkatle takip edilmekte, günlük yaşam pratikleri içerisinde kendisine yer bulmaktadır

Medya kuruluşları sağlık haberciliği konusunda sansasyonel bir yayıncılık anlayışını benimsemekte, olayları haberleştirirken konunun ilgi çekecek, şok yaratacak yönlerini ön plana çıkartarak, olayları adeta seyirlik bir anlatıya dönüştürmektedir. Bu bağlamda yazıll, görsel/işitsel ya da sosyal medyada yer alan sağlık ile ilgili içeriklerin doğru yorumlanabilmesi konusunda sağlık okuryazarlığı becerisi önemli bir yetkinlik olarak karşımıza çıkmaktadır.

Sağlık alanında hazırlanan haberlerde genellikle sansasyonel ve abartılı bir haber dili kullanılmakta olup, insanlara umutsuzluk ya da sahte umut verecek yayınlara sıklıkla rastlanmaktadır. Okuyucunun ilgisini çekmek amacıyla kullanılan abartılı haber başlıkları ile haber içeriklerinin çoğunlukla birbiriyle uyumlu olmadığı göze çarpmaktadır. Ticari kaygı ile hareket eden haber medyasının haber adı altında reklam ya da ürün tanıtımından çekinmediği görülmektedir. Tüm bu sorunlar sağlık haberciliği alanında uzmanlaşmanın gerekliliğine işaret etmektedir.

Sağlık okuryazarlığı kavramı; bireylerin sağlıkla ilgili enformasyonları doğru anlamaları kadar, bu bilgileri günlük yaşamlarında uygulamalarından, sağlık sistemini değerlendirmelerine kadar geniş bir yelpazeye uzanmaktadır.

Sağlık okuryazarlığı düzeyinin yetersiz olması, bireysel ve sosyal açıdan birtakım riskler oluşturmakta, verilen sağlık hizmetlerinin istenilen sonuca ulaşmasına engel olmaktadır. Sağlık okuryazarlı̆g 1 konusunda istenilen bilinç düzeyine ulaşılması, sağlı hizmetlerinin ve sağlığa ayrılan kaynakların etkin kullanımını beraberinde getirdiği gibi, bireysel davranışlarda olumlu değişimlere yol açmaktadır.

Türkiye'de sağlık okuryazarlığı düzeyinin sınırlı ve yetersiz olduğu yapılan araştırmalarla ortaya konulmuştur. Ülkemizde bu konu ile ilgili bilgi eksikliğinin farkına varılmasıyla birlikte çeşitli politikalar geliştirilmiştir. Bu amaçla Sağlık Bakanlığı tarafından 2012-2017 yıllarını kapsayan Stratejik Planı'nda "Bireylerin kendi sağlığı üzerindeki sorumluluğunu artırmak için sağlık okuryazarlığını geliştirmek" hedefi yer almaktadır. Bu hedefi gerçekleştirmek için, "Halk arasında sağlık okuryazarlığı düzeyini tespit etme, izleme ve artırma" ve "Toplumda sağlık okuryazarlı̆gını artırmak için iletişim faaliyetlerini güçlendirme" gibi uygulamaların hayata geçirilmesi öngörülmektedir (Sağlık Bakanlığı, 2015).

Sağlık okuryazarlığı alanında yürütülen bir diğer çalışma ise Sağlık Bakanlığı Kamu Hastaneleri Kurumu Eğitim, Araştırma ve Geliştirme Daire Başkanlığı tarafından gerçekleştirilen "Sağlık Okuryazarlı̆̆ 1 Öğrenimi Sertifika Programı" olmuştur. Bu kapsamda 2016 yilında aile hekimleri ve aile sağlığı çalışanlarına yönelik bir eğitim programı düzenlenmiştir. Aile sağlığı merkezi çalışanlarında farkındalık oluşturarak, hasta ve yakınlarıyla iletişimin güçlendirilmesi hedeflenen projesi kapsamında 81 ilin halk sağlığı müdürlüklerinde ve toplum sağlığı merkezlerinde görevli 400 hekime eğitim verilmiştir.

Literatürde sağl1k okuryazarlığı düzeyinin belirlenmesine yönelik yapılan çalışmalarda çeşitli bulgular elde edilmiştir. Akcilek (2017) tarafından üniversite öğrencilerinin sağlık okuryazarlık düzeyi ile yaşam kalitesinin belirlenmesi amacıyla 870 öğrenci üzerinde gerçekleştirilen çalışmada, öğrencilerin yüzde 47'sinin sağlık okuryazarlığı konusunda yeterli bilgi düzeyine sahip olmadığı görülmüsstür.

Durmaz (2016, s. 114) tarafından sağlık personelinin sağlık okuryazarlığı konusundaki farkındalık ve bilgi düzeyini ölçmek amacıyla 514 sağlık çalışanı üzerinde gerçekleştirilen anket çalışmasında, başta hekimler olmak üzere sağlı çalışanlarının sağlı okuryazarlığg kavramı konusunda yeterli bilgiye sahip olmadığı sonucuna ulaşılmıştır. 
Türkoğlu (2016) tarafından Isparta ilinde yaşayan bireylerin sağlık okuryazarlığı ile özbakım düzeyi arasındaki ilişkisi belirlemek amacıyla 18-65 yaş arasındaki 620 kişi üzerinde gerçekleştirilen çalışmada, sağlık okuryazarlığı ile öz bakım gücü düzeyi arasında anlamlı bir ilişki bulunmuştur.

Gebelerin sağlık okuryazarlığı düzeyini belirlemek amacıyla Filiz (2015) tarafından Konya ili merkezinde yaşayan 20-29 yaş arası 300 gebe üzerinde yapılan araştırmada, gebelik döneminde sağlığı koruyucu ve geliştirici çalışmaların yeterince yapılmadığını otaya koymuştur.

$\mathrm{Bu}$ ve benzeri çalışmaların gösterdiği gibi ülkemizde sağllk okuryazarlığ 1 konusunda toplumun hemen her kesiminde bilgi eksikliği bulunmaktadır. Bu alanda farkındalık oluşturarak, bireylerin sağlık okuryazarlığı seviyesinin yükseltilmesi adına ilgili tüm kesimlere büyük sorumluluklar düşmektedir.

\section{KAYNAKÇA}

Adak, N. (2002). Sağlık sosyolojisi. Kadın ve kentleşme. İstanbul: Birey Yayınları.

Akcilek, E. (2017). Üniversite ögrencilerinde sağlık okuryazarlı̆̆ ve yaşam kalitesinin incelenmesi. Yayımlanmamış yüksek lisans tezi, Medipol Üniversitesi Sağlık Bilimleri Enstitüsü, İstanbul.

Binark. M., Gencel,B, .M.Bek (2007). Eleştirel medya okuryazarlı̆̆ı. İstanbul: Kalkedon.

Durmaz,Y. Yayan, E.Sezgin H.(2016). Sağlık personelinin sağlık okuryazarlığı kavramı hakkındaki bilgi düzeyi. Korunalp Tip Dergisi, 8(2), 114-117.

Durusu Tanrı̈ver, M. vd. (2014). Türkiye sağlık okuryazarlı̆̆ı araştırması. Ankara: Sağl1kSen $\quad$ Yayınlar. $\quad 15 \quad$ Kasım $2017 \quad$ tarihinde http://www.sagliksen.org.tr/cdn/uploads/gallery/pdf/8dcec50aa18c21cdaf86a2b33001a 409.pdf adresinden erişildi.

Filiz, E.(2015). Sağlık okuryazarlığının gebelik ve sağlık algısı ile ilişkisi. Yayımlanmamış doktora tezi, Selçuk Üniversitesi Sağlık Bilimleri Enstitüsü, Konya.

Hülür, A.B.(2016). Sağlı iletişimi, medya ve etik: bir sağl1k haberinin analizi. Celal Bayar Üniversitesi, Dergisi, (2), s.15-23

http://www.saglik.gov.tr/ 15 Kasım 2017 tarihinde erişilmiştir.

Kaya, A. , Yüksel.E., Öğüt.P. (2011). Sağl1k haberlerinde mucize tedaviler. Selçuk İletişim, 7(1), 49-64.

Nutbeam, D. (2001). Health literacy as a public health goal: A challenge for contemporary health education and communication strategies into the 21 stcentury. Health Promotion International, 15(3), 259-267.

Osborne, H. (2005). Health literacy from A-Z, USA: Jones and Bartlett.

Parker.R.M vd. (1995). The test of functional health literacy in adults: A new instrument for measuring patients. literacy skills. Journal of General Internal Medicine, 10(10), 537541.

Parker,R.M.(2003). Health literacy: A policy challenge for advancing high-quality health care. Health Affairs, 22(4), 147-153.

Parvanta R.(2011). Essentials of public health communication, USA: Jones and Bartlett.

Ratzan, S.C. (2001). Health literacy: Communication for the public good. Health Promotion International, 16(2), 207-214. 
Sağlık Bakanlığı (2015). Stratejik plan 2013-2017. 15 Kasım 2017 tarihinde http://www.sgb.saglik.gov.tr/content/files/stratejikplan20132017/index.html adresinden erişildi.

Selden, C. R.(2000). Health literacy. USA: US Department of Health and Human Services.

Sezgin, D. (2011). Tıbbileştirilen yaşam bireyselleştirilen sağlık. İstanbul: Ayrıntı Yayınları.

Türkoğlu,Ç.(2016). Să̆lık okuryazarlı̆̆ ile özbakım gücü arasındaki ilişkinin incelenmesi: Isparta ili örneği. Yayımlanmamış yüksek lisans tezi, Süleyman Demirel Üniversitesi Sosyal Bilimler Enstütüsü, Isparta.

Türkoğlu,N.(2007). Okuryazarlıktan medya okuryazarlığına: Şifrelerin ortaklığını aramak. Medya okuryazarlı̆̆ İstanbul: Kalemus. s. 276-283.

Yılmazel, G., Çetinkaya, F. (2016). Sağlık okuryazarlığının toplum sağlığı açısından önemi. TAF Preventive Medicine Bulletin, 15(1), 69-74.

Zarcadoolas, C.(2005). Understanding health literacy: An expanded model. Health Promotion International, 20(2), 195-203. 